\title{
Foreignising versus Domesticating Translations of Arabic Colour-related Expressions
}

\author{
Amal Abdelsattar Metwally \\ English Department, Faculty of Languages and Translation, King Khalid University, Abha, Saudi Arabia
}

\begin{abstract}
The present study attempts to focus on the translation of colour-related idioms and binomials as culture-specific expressions and questions the validity of the notions of foreignisation and domestication brought to the fore of translation studies by Venuti (1995). However, it is not intended here to question the quality of Venuti's advocacy of foreignising translation, but rather to apply the notions of foreignisation and domestication, as well as paraphrase as one mode of domestication in translating colour-related expressions. More particularly, the study examines whether it is possible to observe any form of consistency in the strategies used for the translation of such culturally-bound expressions. This is attempted under the framework of the skopos theory and Berlin/Key studies on colours (1969). The paper describes alreadyexisting translations in order to make generalizations about translation methods. Such generalization may be taken as guidelines for the translation of culture-bound expressions in general. The present study explores the translation of 84 Arabic colour-related expressions, and reaches the conclusion that "paraphrase" is a significant strategy for translating Arabic colour-related expressions into English due to the distant cultural backgrounds and the divergent historical affiliations of the two languages.
\end{abstract}

Index Terms - colour-related expressions, idioms, binomials, Skopos theory, foreignisation, Domestication

\section{INTRODUCTION}

Languages may differ from one another to a great degree, but this does not mean that translation is not possible. Translation does not only involve giving the equivalent meaning in the target language (TL), rather it involves considering the values of the (TL). Some translators prefer changing the source language (SL) values and bringing them 'closer' for the (TL) receivers. This translation strategy is termed domestication. Other translators, on the other hand, prefer preserving the values of the (SL) as well as exposing them to (TL) receivers. This translation strategy is termed foreignisation (Domestication and Foreignization in Translation, 2011).

Idioms are linguistic clichés which use frozen expressions. Longman Idioms Dictionary (1998) defines the term idiom as "a sequence of words which has a different meaning as a group from the meaning it would have if you understand each word separately" (p. vii). Lewis provides another concise dictionary-like definition: an idiom, he states, is "a multi-word lexical item where the meaning of the whole is not directly related to the meanings of the individual words" (1998, p. 217). Cowie and Mackin (1975) also emphasise the multi-word nature and semantic opacity of idiom (p. viii). An idiom, they write, "is a combination of two or more words which function as a unit of meaning". With idioms, then, we cannot look at the individual words of the expression and describe the meaning that each makes to

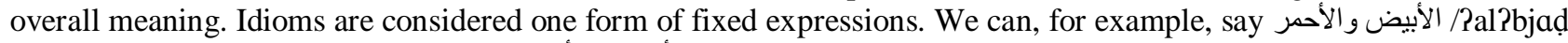
wal Phmar/ (i.e. money) but never * الأحمر والأبيض /21PhmarwalPbjaḍ/. According to Crystal (1988) an idiom is "a sequence of words which is semantically and often syntactically restricted, so that they function as a single unit" (p. 189). From a semantic viewpoint, the meanings of the individual words cannot be summed to produce the meaning of the idiomatic expression as a whole.

Colours have received much attention in linguistics because of their apparently universal character. All humans with normal vision can see colours and names are given in order to make reference to them. But not all cultures name all colours, and colours realization differs from language to language, culture to culture (Philip, 2006). As such, despite recent developments in the field of translation theory, idioms, especially such culture-bound expressions as colourrelated idioms, still cause problems that relate to two main areas: recognising and interpreting them properly and rendering the 'intended' meaning into the target language (Baker, 1992, p. 68). For such culturally-bound expressions, the study proposes the adoption of the foreignisation strategy of translation along with a paraphrase of the expression or domestication depending on the idiom transparency and the possibility of rendering it to an equivalent in the (TL).

\section{LITERATURE REVIEW}

This literature review explores the notions of foreignisation and domestication and their application to translations of Arabic colour-related expressions. "Paraphrase", as a domestication-biased technique is explored as well to verify that it is a powerful strategy to be adopted in handling such culture-specific expressions.

Translation of Culture-bound Expressions 
Many studies have been conducted on cross-cultural differences and the translation of idioms as culture-specific expressions. Su-Ju (2006), for example, discusses how to apply the functional equivalence model to English and Chinese translation. Guntathong (2006) analyses English love-related idioms, and Hongxiang (2005) investigates the translation of idioms between English and Chinese. Moreover, Colin (2006) carries out a study in which English and Swedish animal idioms were contrasted and translated.

Most significantly, many studies have been carried out on the translation of English and Arabic idioms. For example, Mahmoud (2004) examines the interlingual transfer of idioms by Arab learners of English; while Homeidi (2007) deals mainly with some of the difficulties the translator might encounter when translating some culturally bound expressions. Awwad (1990) analyses the equivalence and translatability of English and Arabic idioms; while Abu-Ssaydeh (2004) focuses on the translation of English idioms into Arabic. Abdullah and Jackson (1998) investigate what types of Syrian Arabic idioms are most likely to be transferred while learning a second language. Zughoul and Hussein (2001) examine Arabic-speaking learners' ability to provide translations of idiomatic expressions and collocations. Moreover, AlHasnawi et al. (2007) investigates the 'untranslatability' of some Arabic metaphors into English and finds that most metaphors are shaped by the socio-cultural beliefs and attitudes of a specific culture.

In the light of the aforementioned review, culture- bound expressions and translation strategies can be conceptualised as follows: culture bound expressions are unique to a language and cannot be understood simply from the meaning of their individual words and they require an adequate cultural awareness of the (SL) and the (TL) (Badawi, 2008). In this study, cultural expressions are limited to Arabic colour-related idioms.

\section{Colour-related Idioms}

Because of its thorough scope, Berlin/Kay's (1969) survey of colour terms provides a platform for most linguistic and translation research involving colours. The aim of studying them is to identify the basic colour terms for each of the languages studied, and the order in which these come into use, with a view to identify a mechanism towards the acquisition of colour terms in languages as a whole (Berlin/Kay 1969, p. 5ff).

When dealing with colour-related idioms, the notion of literal meaning is very problematic, as the only true literal meaning of a colour-related expression is found in its popular capacity; the sun is yellow, the sky is blue or grey, blood is red. When used in this way, colour terms carry no meaning other than the representation of hue. Instead of literal, it is helpful to speak of colour as having prototypical meaning (Philip, 2006, p. 1). One way of identifying the range of shades to which the prototypical colour can be extended is to study structures in which a real-world object is compared to a colour. For example, the English idiomatic expression whiter than white شديد النقاء/Jadiidul-naqaa?/, refers specifically to moral purity through the connotative values of 'white' in religion. Semi-opaque expressions require more أشد بياضًا من مروج جبال الألب الخضراء في ديسمبر/2/adu-bajaḍan-min-murudzi-dzibalu-PlPlbi Plxaḍraa?-fi disambir/ requires a degree of semantic elaboration before the oblique references to snow is identified, i.e. that a mountain region in mid-winter is assumed to be covered with snow and therefore white (Philip, 2006).

\section{Colour- related Binomials}

Binomials are defined as a term to refer to conjoined pairs that are unrestricted to certain word classes. However, they occur in fixed 'frozen' order as idiomatic expressions (Moon 1998 as cited in Malkiel 1959; Makkai 1972). In fact, some binomials are not irreversible but still demonstrate clear tendencies for preferred ordering. For example, in Arabic the binomial expression أبيض وأسود/Pbjaḍ-wa-Pswad/ (i.e. white and black) is preferred to أسود وأبيض /Pswad wa- Pbjaḍ/ (i.e. black and white), and vice versa in English.

Like idioms, translating binomials could be problematic. The Arabic binomial الموت الأحمر/Plmawtu-PlPhmar/ is usually used to refer to patience in confronting life's hardships. Instead of translating it into Red death, paraphrase could be adopted to get, for example, the English rendering 'patience in hardships'. Actually, the choice of this translation is due to the fact that Red death is differently used in the English culture. In English, Red death comes from "The Masque of the Red Death", originally published as "The Mask of the Red Death" (1842), a short story by Edgar Allan Poe. In this story, Red death is used as a symbol of the inevitability of death. However, it is not the meaning intended in the Arabic expression الموت الأحمر/2lmawtu-?l?hmar/.

\section{The Relationship between Translation and Culture}

Languages do not operate in isolation; they are linguistic reorientations of cultures. Hence, translation adopts a significant role in bringing cultures closer through the appropriate rendering of (SL) into the (TL). In essence, translation has often been thought of as a source of cultural renaissance. This view is explained by Delille:

I have always thought of translation as a way to enrich a language. If you write an original work in a particular language you are likely to exhaust that language's own resources, if I may say so. If you translate, you import the riches contained in foreign languages into your own, by means of felicitous commerce (as cited in Lefevere, 1992, p. 37).

Such kinds of views support the idea that translation has the potential to promote intercultural communication. Translating into a (TL) in a meaningful sense requires understanding the cultural context of that target language. According to Nida (1964), "differences between cultures may cause more serious problems for the translator than do differences in language structure" (p. 130). As such, both language and culture should be highly considered in the act of translation especially in the process of translating culturally-bound expressions.

Translation of culture-bound expressions 
According to Newmark (1988), multi-word expressions as idioms are some of the most challenging translation difficulties (p. 104). Translating idioms is difficult, since idioms are frozen chunks of words whose overall meaning differ from the meanings of the words involved. Cultural expressions are a crucial translation problem, especially when translating between two distinct languages that are spoken by two distant nations (Balfaqeeh, 2009).

Reviewing literature pertinent to translation reveals that the difficulty of translating cultural aspects has led to 'culture marginalisation' during the 1960s and 1970s. It has been long taken for granted that translation deals only with linguistic aspects. However, cultural elements have never been brought into discussion. For Nida and Taber (1969) the process of translation consists of reproducing the closest equivalent of the (SL).

\section{Foreignisation versus Domestication}

One of the main notions on which the present study is based is Venuti's notion of the translator's invisibility. The terms 'foreignisation' and 'domestication' have been coined by Venuti (1995) as a means of providing a classification of translation strategies. Venuti (1995) indicates that translation strategies "involve the basic tasks of choosing the foreign text to be translated and developing a method to translate it" (p. 240). He employs the concepts of domesticating and foreignising to refer to translation strategies (1998, p. 67). To Venuti, domestication, or translator invisibility, consists in translating in a clear and intelligible way which erases the foreignness of the source text in order to meet the needs and values of the target culture (Ramiere, 2006). Similarly, paraphrase, as a domestication-biased technique tends to restate the meaning in a clearer form in order to smoothly transfer the embedded message from the (SL) to the (TL). By adopting 'paraphrase', a translator is free from abiding by the grammatical structures of the (SL). As such, a translator can produce more accurate renderings owing to the freedom given to him/ her from being committed to certain idiomatic structures.

\section{The Skopos Theory}

In the process of translation, an appropriate strategy should be mainly determined by the skopos, or purpose of the translation. If a translation is intended to widen the target addressees' visions and to introduce the source culture to the target audience, the translator may choose to adopt the foreignisation strategy in rendering the equivalent meaning. On the other hand, if the skopos is to provide a clear-cut translation for common readers, the domesticating method may be adopted (Zhao, 2008). In other words, the end justifies the means.

It follows that a gap in the literature that this paper is intended to fill is how to translate such culturally-bound expressions as colour-related idioms and binomials.

\section{MethodOLOGY}

The study relies on Venuti's (1995) distinction between foreignisation (SL-oriented translation) and domestication (TL-oriented translation) towards translating colour-related expressions. The former is a parallel word-for-word translation that aims at rendering the form of the (SL) into the (TL) and the latter is a 'facilitated' translation that aims at conveying the meaning of the (SL) rather than the form. "Paraphrase" is presented as a powerful tool that is used in translating such culturally-bound expressions to the effect of creating a liberal, approximate translation of the (SL).

To address the gap in the literature (i.e. how to translate such culturally-bound expressions as colour-related idioms and binomials), the present paper employs the two modes of translation distinguished by Venuti (1995); foreignisation and domestication. Moreover, paraphrase is explored as a successful TL-biased technique. To this effect, the theoretical framework makes use of the skopos theory, which incorporates strategies ranging from the most literal (i.e. foreignising) to the freest (i.e. domesticating and particularly paraphrasing).

\section{Employing the Skopos Theory}

According to the functional approaches to translation, there are three vital rules in the skopos theory, namely, the skopos rule, coherence rule and loyality rule. In the functionalist theory of translation, the best rule for any translation is the "skopos rule", which says that a translational action is determined by its Skopos. Skopos rule is to translate in a way which helps the translation to function in an appropriate way for the people who will use it (Reiss \& Vermeer, 1984). The translator is the one who will determine as for which particular skopos (i.e. purpose) should be the one to carry out in a translation process.

The coherence rule implies that the translated text should make sense in the communicative situation in which it is delivered (Reiss \& Vermeer, 1984, p. 113). Therefore, the translator should consider the target culture and apply any needed changes in order to make the translation comprehensible.

The third principle of the skopos theory is loyalty principle. It refers to the responsibility the translator has toward the source text, target audience and other agents in the translational environment. This principle demands the translator to be loyal to the source text writer and the target readers, but this does not mean that the translator has always to follow (TL) receivers' expectations (Nord, 2001, p. 125).

Under the framework of skopos theory, foreignisation and domestication may not contradict with each other. Since any translation generally involves various purposes, different strategies have to be taken in order to achieve each of them. The two strategies can be combined by adopting paraphrase; a domestication-biased technique. It is to render the meaning of the expression clearly and intelligibly in the target language.

The corpus data consists of a list of 84 Arabic colour-related expressions collected mainly from Almawrid English Dictionary, Hans Wehr's, A Dictionary of Modern Written Arabic, and the Arabic lexicon Almujam Alwaseet. 


\section{Foreignisation (SL-oriented translation):}

The term foreignisation (SL-oriented translation) can be translated into التغريب (إضفاء الطابع الأجنبي). This strategy, which translates an idiom by the nearest equivalent idiom in the target language, works in two modes: a mode in which there happens to be a (TL) replica of a (SL) idiom and a mode in which the (SL) idiom is translated literally without being unintelligible. Occasionally, one might encounter an Arabic idiom that is a replica of an English idiom. Arabic and English have the idiom white lie أكذوبة بيضاء /?ukðubah-bajiḍa?/ (lit. a lie told to be polite or to stop someone from being upset by telling him the truth). The effect of this strategy, when applicable, is to preserve the impact of the (SL) idiom since the translation maintains the lexical constituents, the semantic content and most importantly the effect of the source text (Abu-Ssaydeh, 2004) (See Table 1.1)

TABLE 1.1

COLOUR-RELATED IDIOMS OF ARABIC ORIGIN THAT ARE FOREIGNISED:

\begin{tabular}{|c|}
\hline 1. أكذوبة بيضاء /Pukðubah-bajiḍaa?/ is translated into white lie. \\
\hline 2. الصليب الأحمر /Pșalib-Plihmmar/is translated into the Red Cross. \\
\hline 3. الحمر اء /Plhamraa?/is translated into Alhambra (the Citadel of Granada). \\
\hline 4. الحمى الصفر اوية/Plhummah-?șșafrawijiah/ is translated into yellow fever. \\
\hline 5. 5swad-fahim/ is translated into coal-black, jet black. \\
\hline 6. 6. شاب أخضر/Jab-?xḍar/is translated into green (informal: inexperienced) \\
\hline 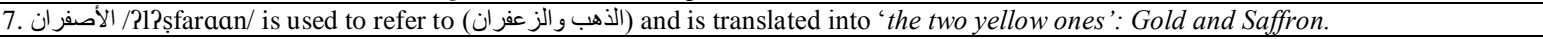 \\
\hline 8. الأحمر ان /Pliphmaraan/the two red ones' is translated into 'gold and saffron', 'meat and wine', or 'bread and meat'. \\
\hline 9.9. اصفر الزرع/Pișfara-?zzarGu/is used to refer to the withering process of plants, and is translated into turned into yellow. \\
\hline 10. 10. Pirtadah-Plbajaaḍ/translated into to dress in white. \\
\hline 11 البيض /Plbjiidel/ is translated into the white race. \\
\hline 12. اللبن والماء and so that it is translated into 'the two white ones: milk and water.. \\
\hline 13. الأسودان /Pl?swadaan/ is translated into 'the two black ones' to refer to date and water, water and milk, or the serpent and the scorpion'. \\
\hline
\end{tabular}

\section{Domestication (TL-oriented translation):}

Although idioms are thought of as being bound to cultures, many idioms have equivalents across many different languages. However, cultural differences and the various historical backgrounds make the number of Arabic idioms that are of complete equivalence to English idioms very limited. In many cases, the semantic content is the same but the linguistic realization is totally different. In such types of idiomatic expressions, domestication can provide an appropriate translation (Abu-Ssaydeh, 2004).

The term domestication (TL-oriented translation) can be translated into التوطين (إضفاء الطابع المحلي). Like foreignisation, the domestication strategy works in two modes: a mode in which there is an equivalent idiom in the TL and a mode which provides a paraphrase of the expression. For example, when the English idiom Purple Heart (i.e. American medal given to soldiers who have been injured in war) is translated into Arabic using the foreignisation strategy it will produce القب الأرجواني/Plqalbu-PlPurdzuwanii/, which will be unintelligible to the Arabic-speaking receiver. In its first model, the domestication strategy will, however, produce وسام جرحى الحرب/wisam-dzarha-Plharb/, which is more appropriate. In such cases an English idiom can be translated by applying the domestication strategy, i.e. finding an idiom in the (TL) which is semantically equivalent to the English idiom (Abu-Ssaydeh, 2004) (See Table 1.2) 
TABLE. 1.2

COLOUR-RELATED IDIOMS OF ARABIC ORIGIN THAT ARE DOMESTICATED:

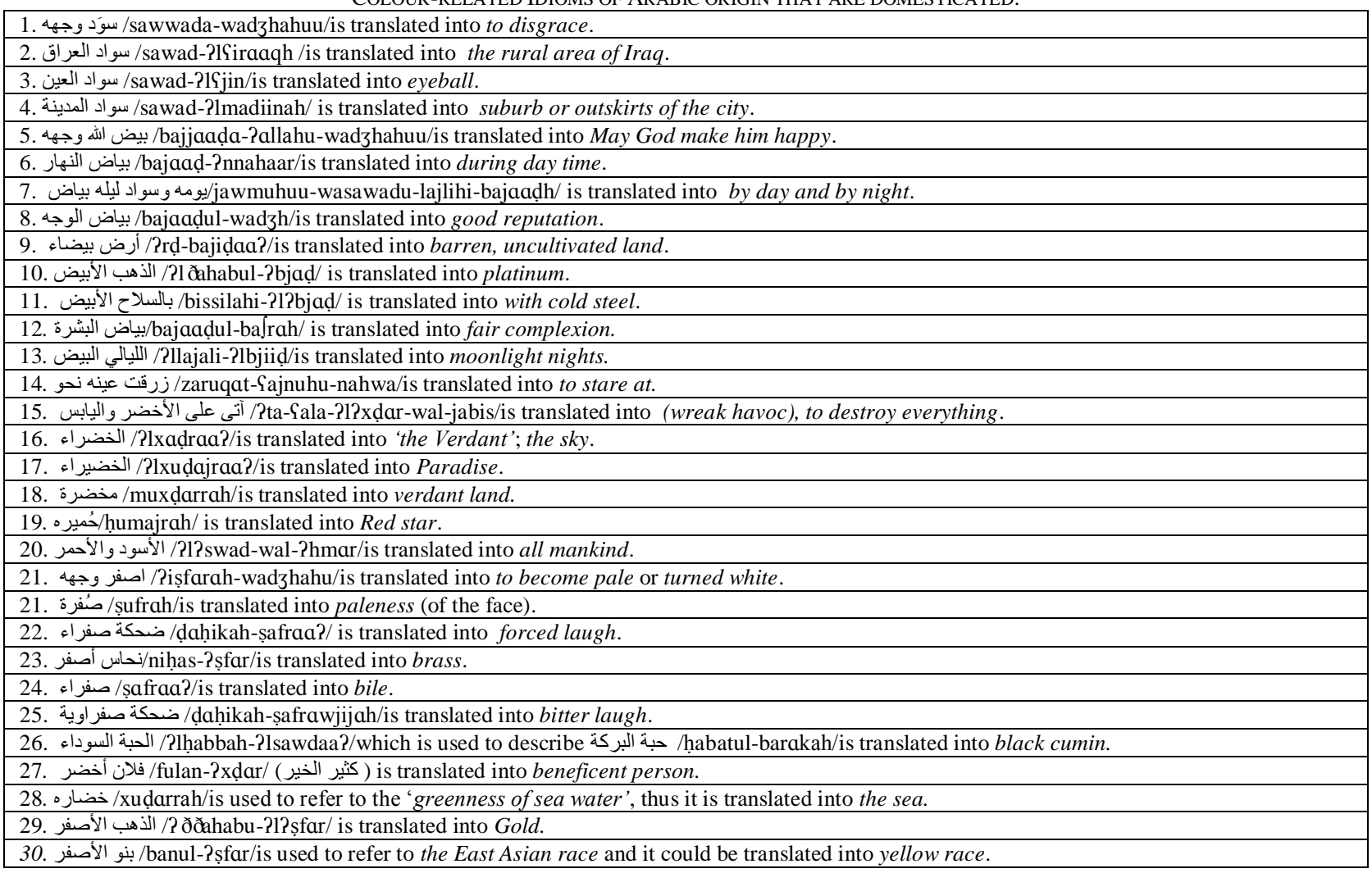

\section{Paraphrase (domestication-biased strategy)}

The second mode of domestication, "paraphrase", is defined by Baker (1992) as "expressing the meaning of an item in other words because no match can be found in the (TL) or because of differences in stylistic preferences of the (SL) and (TL)" (p. 71-78). This is by far the most common way of translating idioms when a match cannot be found in the target language or when it seems inappropriate to use idiomatic language in the target text because of differences in stylistic preferences of the source and the target languages (Baker, 1992, p. 74-75).

Among the advantages of this method is producing more accurate renderings due to the freedom allowed to the translator from being committed to idiomatic structures. Thus, whenever the two cultures and the languages in question are very different, paraphrasing tends to be the most acceptable strategy (Abu-Ssaydeh, 2004, p. 6) (See Table 1.3). 
TABLE 1.3

COLOUR-RELATED IDIOMS OF ARABIC ORIGIN THAT ARE TRANSLATED INTO ENGLISH USING THE PARAPHRASE STRATEGY:

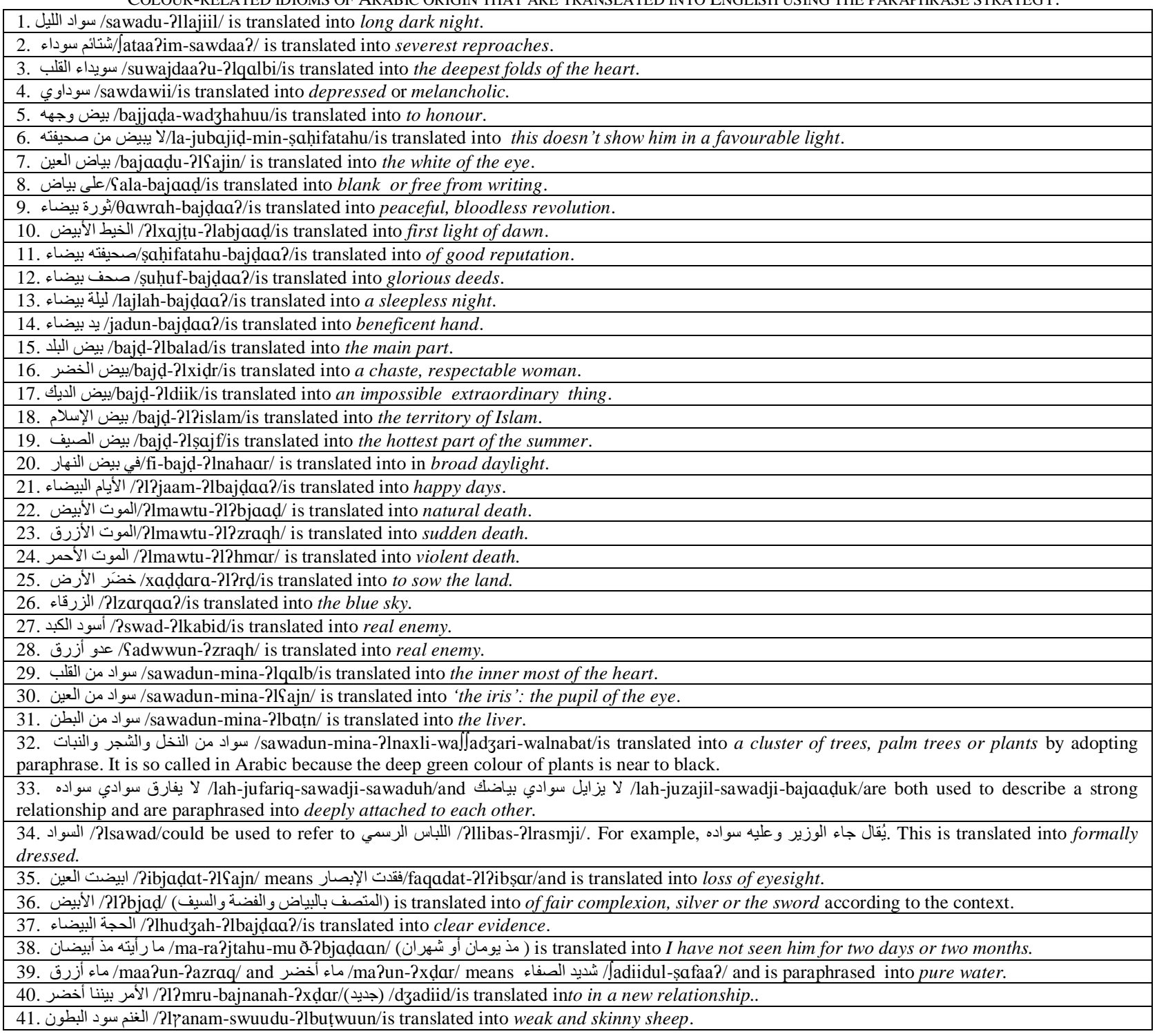

\section{RESULTS AND DISCUSSION}

The above analysis thus shows that such complex and culture-specific multi-word units as colour-related idioms and binomials can be translated through a variety of strategies, depending on the idiom itself, its cultural background and the relationship between the (SL) and the (TL). Long debates have been held to discuss when to paraphrase, when to use the nearest local equivalent by adopting domestication and when to translate literally by adopting foreignisation. However, the above analysis has shown that along with foreignisation and domestication, culture-bound expressions as colour-related idioms are smoothly translatable by adopting "Paraphrase". The translator is allowed to stand in a middle- position between foreignisation and domestication by applying paraphrase.

The results of this data analysis show that:

1. Thirteen Arabic colour-related expressions of the total corpus of eighty four expressions have been translated into English by using foreignisation as in the translation of أسود فاحم/2swad-fahim/ into 'coal black' or 'jet black', and الأحمران/Rl?hmaraan/, into 'gold and saffron', 'meat and wine', or 'bread and meat'. By applying this strategy, a (SL) idiom is replaced by a (TL) idiom or replica that serves the same purpose in the target language culture.

2. Thirty Arabic colour-related expressions have been translated by adopting the domestication strategy as in translating آتى على الأخضر واليابس (dahikah-ṣafraa?/ into 'forced laugh' anda-Pl?xḍar-wal-jabis/ into 'wreak havoc'.

3. Forty one Arabic colour-related expression have been translated by adopting the paraphrase approach as in translating سويداء القلب /2uwajdaa?u-Plqalbi/ into 'the deepest fold of the heart'. 
Based on the above findings, the field of translation studies should not be rent by dichotomies of the nature of domestication and foreignisation. Foreignisation and domestication along with paraphrase complement each other. However, these strategies of translation cannot always be used interchangeably.

\section{CONCLUSION}

The difficulty of translating culturally-bound expression as colour-related idioms and binomials lies in the fact that they can be quite different across cultures and languages. This study has explored the translation of a number of Arabic colour-related idioms within the overall context of Venuti's domestication and foreignisation dichotomy. It is a practical attempt to demonstrate that different modes of translation complement each other. "Paraphrase" as a mode of domestication is a powerful strategy in translating Arabic colour-related expressions that can be applied when no equivalent is found in the (TL) because of cultural divergences. Colours, as culture-bound terms were used to verify that different translation strategies should be adopted in the process of translating between two distinct cultures. It can be inferred from this study that domestication strategies, including paraphrasing and translation using equivalents, were more favourably practicle than foreignisation which results sometimes in literal translation. Some of the foreignised translation choices of colour-related idioms in the corpus data were accompanied with explanations. In other words, if an expression does not have a replica in the (TL), or direct equivalents for idioms as cultural expressions are not available, paraphrasing would be sufficient and acceptable to the target audience.

\section{REFERENCES}

[1] Abdullah, K., \& Jackson, H. (1998). Idioms and the language learner: Contrasting English and Syrian Arabic Languages in contrast, vol. 1, 83-107. Retrieved August 13, 2010, from: <http://www. cat.inist.fr/? A aModele= afficheN \&cpsidt $=1554850 />$.

[2] Abu-Ssaydeh, A. (2004). Translation of English idioms into Arabic. Retrieved August 15, 2010, from: $<$ http://www.benjamins.com/cgi-bin/t_articles.cgi?bookid=Babel50 $: 2 \&$ artid = 237052692>.

[3] Al-Hasnawi, R., Mohammada, Q., \& Mohammed, N. (2007). Cogno-Cultural Issues in Translating Metaphors, Jordan University of Science and Technology. Retrieved July 21, 2010 from: <http://www.informaworld.com/smpp/title content= t794297831>.

[4] Al-Mawrid English Dictionary, R Baalbaki - Beirut (Lebanon): Dar El-Ilm Lil-Malayin, (1990).

[5] Almujam Alwaseet [Alwaseet Lexicon] (1972). Publisher: Majmaa Allugha AlArabiya, third edition. Egypt: Cairo.

[6] Awwad, M. (1990). Equivalence and translatability of English and Arabic idioms, Yarmouk University, Irbid. Retrieved February 18, 2011 from:〈http:// www.lib.umich.edu/area/Near.East/ALSLING .html - 374k>

[7] Badawi, M. (2008). Investigating EFL Prospective Teachers' Ability to Translate Culture-Bound Expressions (Doctoral Dissertation, University of Tabuk, KSA). Retrieved on September 15, 2018 from https://files.eric.ed.gov/fulltext/ED503396.pdf

[8] Baker, M. (1992). In Other Words. London and New York: Routledge.

[9] Balfaqeeh, N. (2009). Strategies for Translating Idioms and Culturally-bound Expressions within The Human Development Genre, MA thesis, The University of Birmingham.

[10] Berlin, B. \& Kay, P. (1969). Basic Colour Terms: Their Universality and Evolution. Berkeley: University of California Press.

[11] Colin, N. (2006). The Translation of English and Swedish Animal Idioms. Karlstad University, Division for Culture and Communication.

[12] Cowie, A. \& Mackin, R. (1975). Oxford Dictionary of Current Idiomatic English, Vol. 1, Oxford: Oxford University Press.

[13] Crystal, D. (1988). The English language, Harmondsworth: Penguin.

[14] Domestication and Foreignization in Translation. (2011). Retrieved on September 27, 2018 from https://www.studymode.com/essays/Domestication-And-Foreignization-In-Translation-676278.html.

[15] Guntathong, W. (2006). An Analysis of English Love Idioms and their Translation into Thai, A term paper presented to the faculty of Liberal Arts Retrieved February 21, 2011 from: <http://www.rsu.ac.th/libarts/new/ English/ Program\%20IS/ 141160/00141.pdf/>.

[16] Hans Wehr's. (1976). A Dictionary of Modern Written Arabic. London: Harrap [etc.].

[17] Homeidi, M. (2007). Arabic Translation across Cultures, John Benjamins Publishing Company. Retrieved March 16, 2011 from: <http://www.writing.com/main/view_item/item_id/1346384- 98k/>.

[18] Hongxiang, O. (2005). Culture differences and the translation of idioms between English and Chinese: MA thesis, Guizhou University for Nationalities.

[19] Lefevere, A. (1992). Translation/ History/ Culture: a Sourcebook. New York: Routledge.

[20] Lewis, M. (1998). Implementing the lexical approach. London: Language Teaching Publications.

[21] Longman Idioms Dictionary. (1998). Longman, Harlow, England, ISBN.

[22] Mahmoud, A. (2004). Interlingual Transfer of Idioms by Arab Learners of English. Sultan Qaboos University, Sultanate of Oman. Retrieved March 26, 2011 from:<http://www.teslj.org/Articles/Mahmoud -Idioms.html - 18k/ >.

[23] Malkiel, Y. (1959). "Studies in Irreversible Binominals". Lingua (8): 113-160.

[24] Newmark, P. (1988). A textbook of Translation, New York: Prentice- Hall.

[25] Nida, A. \& Taber, C. (1969). The Theory and Practice of Translation, Leiden, Brill.

[26] Nida, E. (1964). Toward a Science of Translating - Leiden; ej Brill.

[27] Nord, C. (2001). Translation as a Purposeful Activity: Functionalist Approaches Explained. Shanghai Foreign Language Education Press. China: Shanghai.

[28] Ordudari, M. (2007). Translation procedures, strategies and methods, Translation Journal, (11), 3-4.

[29] Philip, G. (2006). Connotative Meaning in English and Italian Colour-Word Metaphors. Metaphorik (10), 59-61. 
[30] Ramiere, N. (2006). Reaching a Foreign Audience: Cultural Transfers in Audiovisual Translation. Retrieved August 20, 2010 from: $\mathrm{http}: / / \mathrm{www}$.jostrans.or/ issue06/art_ramiere.pdf.

[31] Reiss, K. \& Vermeer, H. (1984). Groundwork for a General Theory of Translation. Tubingen: Niemeyer. Retrieved March 13, 2011 from: frontcover $\& \mathrm{dq}=$ culture+and+translation $\# \mathrm{v}=$ onepage $\& \mathrm{q}=\& \mathrm{f}=\mathrm{false}>$.

[32] Su-Ju, L. (2006). On How to Achieve Functional Equivalence in Translation between Chinese and English. Retrieved October 27, 2011 from: <http://www.linguist.org.cn/ doc/su200612/su20061215.pdf/>.

[33] Venuti, L. (1995). The Translator's Invisibility: A History of Translation. London and New York: Routledge.

[34] Venuti, L. (1998). The Scandals of Translation: Towards an Ethics of Difference. London and New York: Routledge.

[35] Zhao, N. (2008). Domestication and Foreignisation, School of Interpretation and Translation, Shandong University, Weihai, Shandong.

[36] Zughoul, M. \&, Abdul-Fattah, H. (2001). Collocational Competence of Arabic Speaking Learners of English: A Study in Lexical Semantics. Retrieved April 23, 2011 from: <http:/www.eric.ed.gov/ERICWebPortal/recordDetail?accno=ED479650$29 \mathrm{k} />$.

Amal A. Metwally is a lecturer of linguistics and translation at faculty of languages and translation, King Khalid University, Abha, Saudi Arabia. Her main area of interest is translation and culture, technology in foreign language instruction and computational linguistics. She got her MA in translation and she is currently a PhD researcher. She is affiliated to King Khalid University, Saudi Arabia. She is a certified TOFEL and IELTS Trainer. She is also a member of KSAALT TESOL (Kingdom of Saudi Arabia Association of English Language Teachers). 